\title{
BMJ Global Health Health systems factors impacting the integration of midwifery: an evidence- informed framework on strengthening midwifery associations
}

\author{
Cristina Mattison (D , ${ }^{1}$ Kirsty Bourret, ${ }^{1}$ Emmanuelle Hebert, ${ }^{2,3}$ Sebalda Leshabari, ${ }^{4}$ \\ Ambrocckha Kabeya, ${ }^{3}$ Patrick Achiga, ${ }^{5}$ Jamie Robinson, ${ }^{6}$ Elizabeth Darling ${ }^{1}$
}

\begin{abstract}
To cite: Mattison C, Bourret K, Hebert $\mathrm{E}$, et al. Health systems factors impacting the integration of midwifery: an evidence-informed framework on strengthening midwifery associations. BMJ Global Health 2021;6:e004850. doi:10.1136/ bmjgh-2020-004850
\end{abstract}

Handling editor Stephanie M Topp

Received 23 December 2020 Accepted 8 May 202

Check for updates

C Author(s) (or their employer(s)) 2021. Re-use permitted under CC BY-NC. No commercial re-use. See rights and permissions. Published by BMJ.

${ }^{1}$ Obstetrics and Gynecology, McMaster University, Hamilton, Ontario, Canada

${ }^{2}$ University of Quebec at TroisRivières, Trois-Rivieres, Quebec, Canada

${ }^{3}$ Congolese Society of Midwifery Practice, Kinshasa, Democratic Republic of Congo

${ }^{4}$ Obstetrics and Gynaecology, Muhimbili University of Health and Allied Sciences, Dar es

Salaam, Tanzania

${ }^{5}$ Vice-secretary, South

Sudan Nurses and Midwives Association, Juba, South Sudan ${ }^{6}$ Global Programs Manager, Canadian Association of Midwives, Montreal, Quebec, Canada

Correspondence to Dr Cristina Mattison; mattisc@mcmaster.ca

\section{ABSTRACT}

Introduction Midwifery associations are organisations that represent midwives and the profession of midwifery. They support midwives to reduce maternal and newborn mortality and morbidity by promoting the overall integration of midwifery in health systems. Our objective was to generate a framework for evidence-informed midwifery association strengthening.

Methods A critical interpretive synthesis complemented by key informant interviews, focus groups, observations, and document review was used to inform the development of concepts and theory. Three electronic bibliographical databases (CINAHL, EMBASE and MEDLINE) were searched through to 2 September 2020. A coding structure was created to guide the synthesis across the five sources of evidence.

Results A total of 1634 records were retrieved through electronic searches and 57 documents were included in the critical interpretive synthesis. Thirty-one (31) key informant interviews and five focus groups were completed including observations (255 pages) and audio recordings. Twenty-four (24) programme documents were reviewed. The resulting theoretical framework outlines the key factors by context, describes the system drivers that impact the sustainability of midwifery associations and identifies the key-enabling elements involved in designing programmes that strengthen midwifery associations. Conclusion Midwifery associations act as the web that holds the profession together and are key to the integration of the profession in health systems, supporting enabling environments and improving gender inequities. Our findings highlight that in order to strengthen midwifery (education, regulation and services), we have to lead with association strengthening. Building strong associations is the foundation necessary to create formal quality midwifery education systems and to support midwifery regulation and accreditation mechanisms.

\section{INTRODUCTION}

Growing attention is being given to civil society organisations, and health professional associations in particular, and their role in improving policy for the delivery of quality

\section{Key questions}

What is already known?

- Recent modelling projects that with proper investment in universal coverage of midwifery care, up to 4.3 million lives could be saved by 2035 .

- Midwives continue to face systemic barriers due largely to gender inequity.

- Midwifery associations may play a role in improved health outcomes and health systems, yet there is gap in evidence specific to their impacts.

\section{What are the new findings?}

- Midwifery associations are key to the integration of the profession in health systems and to supporting enabling environments.

- Midwifery associations are an example of largely women-led, nationally recognised, civil society organisations, which when properly invested in and considered, improve gender equity and overall access to sexual and reproductive health and rights.

\section{What do the new findings imply?}

- The theoretical framework provides a road map and foundation for understanding the main elements required to build sustainable midwifery associations.

- The framework's visual representation positions associations within health and political systems, providing guiding principles for how to strengthen midwifery across local, national and international levels.

- An improved understanding of what factors create an enabling environment for midwives to reach their full life-saving impacts.

health services. ${ }^{1-3}$ Health professional associations increase access to health services through raising public awareness, lobbying governments and coordinating multilateral efforts to inform decision-makers. ${ }^{1-7}$ Midwifery associations specifically are an important example of largely women-led civil society organisations that are key to improving access to sexual and reproductive health and rights (SRHR). 
Midwifery makes a vital contribution to the provision of high-quality SRHR care ${ }^{9-12}$ and achieving universal health coverage. ${ }^{13} 14$ It is estimated that universal coverage of midwifery-led care, according to international standards and integrated into health systems, can save up to 4.3 millions lives annually by $2035 .^{15}$

Midwifery associations are organisations, most often national, that represent midwives and the profession of midwifery. Importantly, they support midwives to reduce maternal and newborn mortality and morbidity by promoting the overall integration of midwifery services in health systems. ${ }^{813}$ They use gender-responsive approaches to create and manage standards of midwifery care, strengthen clinical skills, advocate for appropriate deployment and remuneration, and accreditation mechanisms to support midwifery education programmes. ${ }^{13} 16$ Midwifery associations uphold the human rights of women and girls. ${ }^{1}$ They are a crucial voice in promoting access to sexual and reproductive health services and championing broader SRHR issues such as gender-based violence. ${ }^{713} 17$

The International Confederation of Midwives (ICM) and United Nations Population Fund, among others, have recently focused international programming on strengthening midwifery associations' capacity, arguing that these efforts are central to building the midwifery workforce and improving SRHR. ${ }^{18}$ Similarly, the Canadian Association of Midwives (CAM) has engaged in reciprocal capacity-building partnerships with midwifery associations since 2008 and is currently partnered with five associations (Democratic Republic of Congo or DRC, Haiti, Somalia/Somaliland, South Sudan and Tanzania). CAM's global work originated from twinning relationships initiated through ICM, recognising that professional associations can collaborate for mutual benefit. ${ }^{8}$ In health systems in Canada, midwives have struggled for professional recognition and integration. ${ }^{19}$ CAM's twinning relationships challenge traditional models for international development, highlighting that support and growth for the profession is bidirectional. ${ }^{8}$ While association strengthening is becoming a growing focus and area of interest of international programming activities, there is limited scholarship to guide the integration of midwifery through strengthening midwifery associations.

To address this evidence gap, we examined CAM's capacity-building work with partner associations to develop a theoretical understanding for approaches to civil society strengthening through women-led civil society organisations. Our work is rooted in intersectional feminist, anti-colonial and collaborative lenses. We view the importance of context as central, and purposefully do not dichotomise between World Bank country income group classifications (ie, high-income countries vs low-income and middle-income countries) as we recognise that improving access to quality SRHR is relevant to all health systems.

We had three aims: (1) to synthesise multiple sources of evidence to address the compass question: "what are the factors that influence midwifery association strengthening?'; (2) to use the example of CAM's programming related to supporting civil society organisations to understand the factors associated with midwifery association capacity building; and (3) to develop a theory and concepts for midwifery association strengthening. The overall purpose was to create a framework for evidenceinformed midwifery association strengthening to leverage the impacts of midwives to improve SRHR.

\section{METHODS}

We conducted a qualitative systematic review using critical interpretive synthesis, complemented by key informant (KI) interviews, focus groups, observations, and document review to inform the development of concepts and theory. Figure 1 illustrates our highly iterative approach to data collection and theory generation and highlights how five types of qualitative data collection informed the processes of triangulation, theory development, testing and generation. These were not discrete processes, but rather overlapped, and were used to create the theoretical framework.

\section{Search strategy and selection criteria}

Critical interpretive synthesis is an interpretive analytical approach which examines both empirical and non-empirical literature to generate concepts, and is well-suited to the development of theoretical frameworks. ${ }^{20}{ }^{21}$ While conventional systematic review methodology is grounded in a tightly formulated research question and study selection criteria at the outset, critical interpretive syntheses are iterative using a compass question that is responsive to the findings generated in the review process and can be modified as gaps in the literature emerge. ${ }^{20}{ }^{21}$ The searches for the critical interpretive synthesis were completed in two main phases. First, we systematically searched electronic bibliographical databases (CINAHL, EMBASE and MEDLINE), in consultation with a librarian. The MEDLINE searches included: midwifery (MeSH) OR midwi* AND (capacity building (MeSH) OR civil OR (professional adj2 (societ* OR organi?ation* OR affiliation*)) OR partnership*). Minor adjustments were made to optimise search strings for CINAHL and EMBASE. Second, we searched SRHR and civil society websites for relevant documents. We also identified additional relevant literature by hand searching reference lists of key publications.

We included documents that provided insight into the compass question and related specifically to health professional associations. We did not include specific exclusion criteria or search limits.

We used an EndNote database to store and manage the search results. After duplicates were removed, two reviewers ( $\mathrm{CM}$ and $\mathrm{KB}$ ) independently reviewed the remaining titles and abstracts and classified records. We retrieved full-text copies of the 'possibly include' documents, and each reviewer independently assessed 


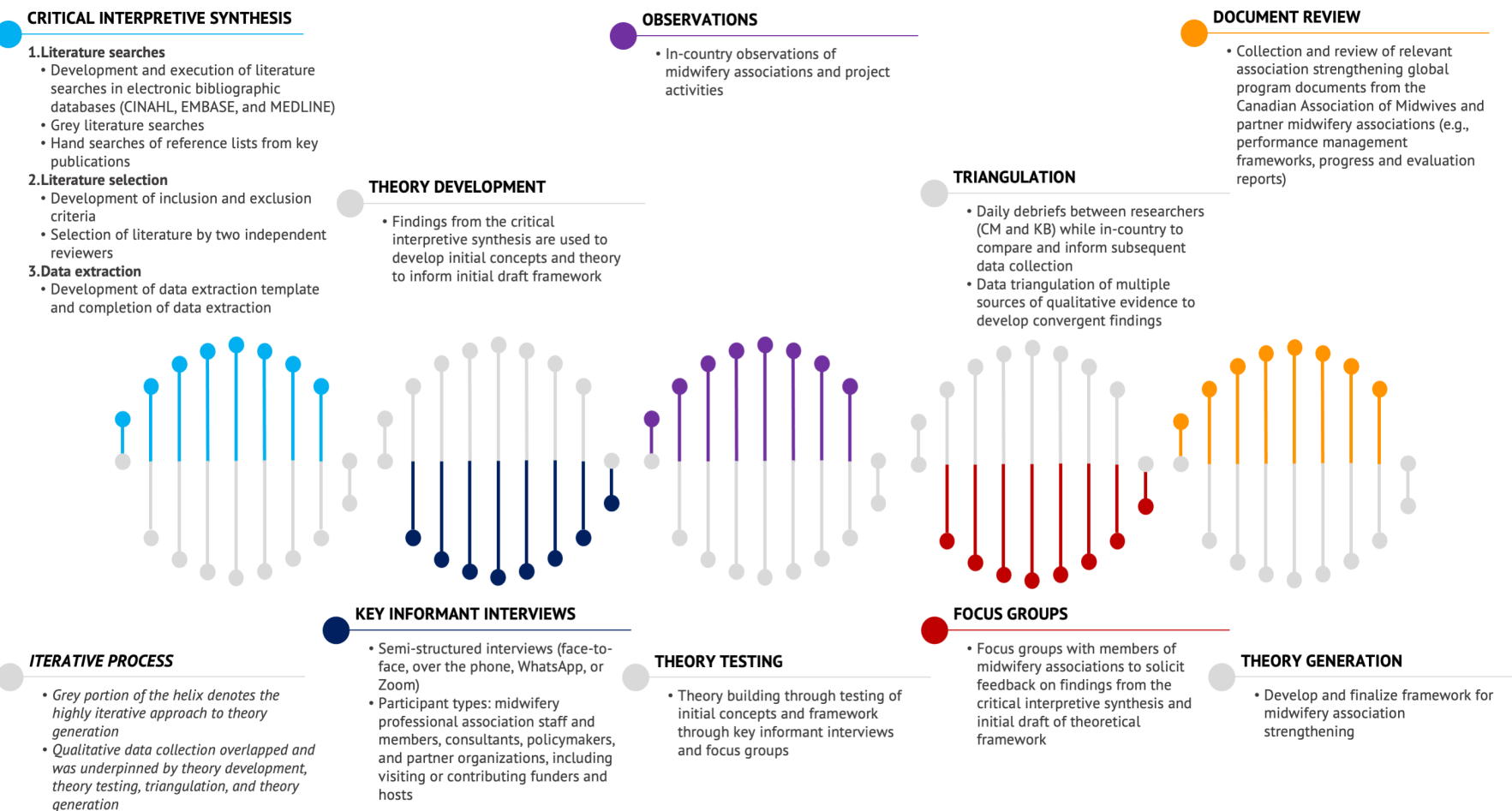

Figure 1 Process helix of qualitative data collection and theory generation.

eligibility for inclusion. Discrepancies were discussed until consensus was reached.

\section{Additional data collection}

We used semistructured KI interviews, focus groups, observations and document review as additional qualitative research methods to inform our theoretical framework. Countries of focus for the additional evidence sources included Benin, Canada, DRC, Ethiopia, Haiti, South Sudan and Tanzania (ie, current or past sites of CAM's global programming). Permission to hold focus groups and interviews in DRC and Tanzania were obtained by in-country midwifery association executives including letters of invitation by associations. Written informed consent was obtained from each participant and data were collected in English or French depending on participant preference.

We used multistage purposive sampling to recruit participants in the following four categories: (1) midwifery professional association staff and members; (2) consultants; (3) policymakers, and (4) partner organisations, including visiting or contributing funders and hosts. We invited participants by email or face-to-face and conducted interviews either face-to-face, by phone or virtually. All interviews were audio recorded.

During data collection in Canada, DRC and Tanzania, we conducted participant observation and focus groups involving the four stakeholder groups outlined. Participant observation was documented through written notes and audio recordings between researchers $(\mathrm{CM}$ and $\mathrm{KB})$.

We used the focus groups to gain a deeper understanding of context-specific factors influencing professional association strengthening and to elicit feedback on the theory emerging from the critical interpretive synthesis.

For the document review, we selected all programme documents (including grant proposals, theory of change and logic models, performance management frameworks, and monitoring and evaluation reports) from CAM projects with a professional association strengthening component. These documents were primarily collected during our time at midwifery association offices and during $\mathrm{KI}$ interviews.

\section{Data analysis}

A common feature of qualitative inquiry is that analysis and interpretation overlap with sampling and data collection (figure 1). Findings from the critical interpretive synthesis informed theory development through the creation of initial core concepts and theory related to professional association strengthening and the initial draft framework. Theory testing was accomplished through additional sources of qualitative data collection by testing iterations of concepts and framework with participants and research consortium in French and English (AK, AP, EH, JR, ED and SL). Rigour was ensured through triangulation of methods and data sources, and to develop convergent evidence. Triangulation was also used as a method of ensuring that we were accurately representing the reality in range of complex settings. Data were collected until data sufficiency was reached, when insights drawn from the analysis stages answered the research question. The framework and concepts were finalised in French and English and validated by the research consortium in their preferred language, which includes midwifery association representation from 
Canada, DRC, South Sudan and Tanzania (AK, AP, EH, JR, ED and SL).

Data extraction for the critical interpretive synthesis was guided by a coding structure. Data were collected on publication year, study design, health professions, jurisdiction(s) of focus based on WHO regions, the processes related to and the characteristics of professional association strengthening. We used a structured Excel spreadsheet to extract data from each included document, including findings pertaining to the processes related to and the characteristics of professional association strengthening. Two researchers $(\mathrm{CM}$ and $\mathrm{KB})$ coded a sample of the documents independently and compared results to ensure consistency in interpretation. These findings were used to develop the initial core concepts, theory and draft framework related to professional association strengthening.

We used NVivo to organise and code the additional qualitative data. Coding occurred in the original language of data collection (French or English). Two researchers independently coded a sample of the transcripts to compare results and check for consistency ( $\mathrm{CM}$ and $\mathrm{KB})$. The remainder of the data was coded by an individual researcher. We applied a constant comparative method such that emerging data were compared with previously collected data to find similarities and differences. ${ }^{22}$ Completeness of the findings was ensured through ongoing consultation with members of the research team (EH and ED).

$\mathrm{CM}$ and $\mathrm{KB}$ were awarded an internship grant to conduct the research for CAM. To support researcher reflexivity, $\mathrm{CM}$ and $\mathrm{KB}$ applied Mertens principles of critical reflection for addressing constructs of power and validity of results. ${ }^{23}$ In this process, we continuously critically examined dynamics of power and our geosocial positioning of privilege to mitigate its impacts on the research process and relationships with participants in order to avoid replicating historical patterns of oppression. Foremost, we recognise that historically, Western knowledge has dominated the global health sector and drives research inquiry and funding. ${ }^{24}$ These reflections resulted in our firm commitment to challenge these aforementioned structures, by intentionally incorporating mitigating measures during inception, operationalisation and completion of the research.

We broadened the research team to include experts in midwifery association strengthening in Canada, DRC, Tanzania and South Sudan. These experts formed a collaborative team and worked with $\mathrm{CM}$ and $\mathrm{KB}$ during the research process (AK, AP, EH, JR, ED and SL). For example, the research inquiry was validated, and initial results were vetted by association members and leadership. The team went on to co-develop the concepts and framework, as well as the manuscript. Finally, there is ongoing collaboration with the research consortium to ensure results are shared with participating associations, which will also include further research to understand the applicability and feasibility of our conceptual elements and checklists. A continuous critical reflection allowed $\mathrm{KB}$ and $\mathrm{CM}$ to retrospectively reflect on shortcomings to their approach, including how other researchers particularly in DRC, Tanzania and South Sudan were remunerated for their contributions, or if transparent discussions occurred regarding authorship order for example.

While collecting data, we were careful to seek perspectives from inside and outside midwifery associations to ensure a variety of voices were heard. We carefully positioned the research as independent to project evaluations to reassure participants that negative opinions would not impact project funding. Finally, in order to understand the impact of gender and intersects (ie, conflict, race, language and ethnicity) on midwifery associations and midwifery within health and political systems, we applied an intersectional framing. ${ }^{25}$ According to the intersectional approach, inequities cannot be linked to distinct factors. Rather they are the result of an intersection of a person or group's social location and the resulting privilege or power causing different forms of domination or exploitation. ${ }^{26}$ This approach was also applied in the analysis and allowed for implicit themes of various forms of oppression shaped by historical and political concepts within the profession of midwifery itself to be developed.

\section{Patient and public involvement}

Due to ethical and feasibility constraints, patients and clients were not involved in the research. However, we recognise that this category is an essential component to understanding the impact and capacity of midwives and midwifery associations in health systems, particularly experiences of care. ${ }^{10}$ We plan to include this component in further research. As discussed in the analysis, a research consortium of midwives and members of midwifery associations across contexts was established at the outset of the research to collaboratively develop the design, data collection, analysis and knowledge exchange.

\section{RESULTS \\ Search results}

Systematic literature searches for the critical interpretive synthesis were completed by 2 September 2020 and results are shown in figure 2. Fifty-seven documents were eligible for inclusion. Most documents (84\%) were published after 2010, and none before 2000. Thirtyseven per cent were primary research $(n=21)$, including: qualitative research $(n=13)$, mixed-methods research $(n=5)$ and descriptive studies $(n=3)$. Within secondary research, $14 \%$ were systematic reviews $(n=8)$ and one was a cross-sectional study. The remaining documents were non-research $(\mathrm{n}=27)$, including 10 'other' (eg, toolkits, manuals, strategic plans, etc), 6 editorials, 5 theoretical papers and 5 non-systematic reviews. In accordance with WHO regions, the majority $(\mathrm{n}=28)$ focused on Africa, 10 on the Americas, 10 on South-East Asia, 6 on the Eastern Mediterranean, 1 on the Western Pacific, 5 on Europe, and $36 \%(\mathrm{n}=17)$ spanned all of the regions. 
PHASE I

Electronic databases: CINAHL, EMBASE and MEDLINE
PHASE II

Initial screen based on title and abstracts
PHASE III

Full text documents assessed by two reviewers for eligibility Extraction and analysis of documents
PHASE IV

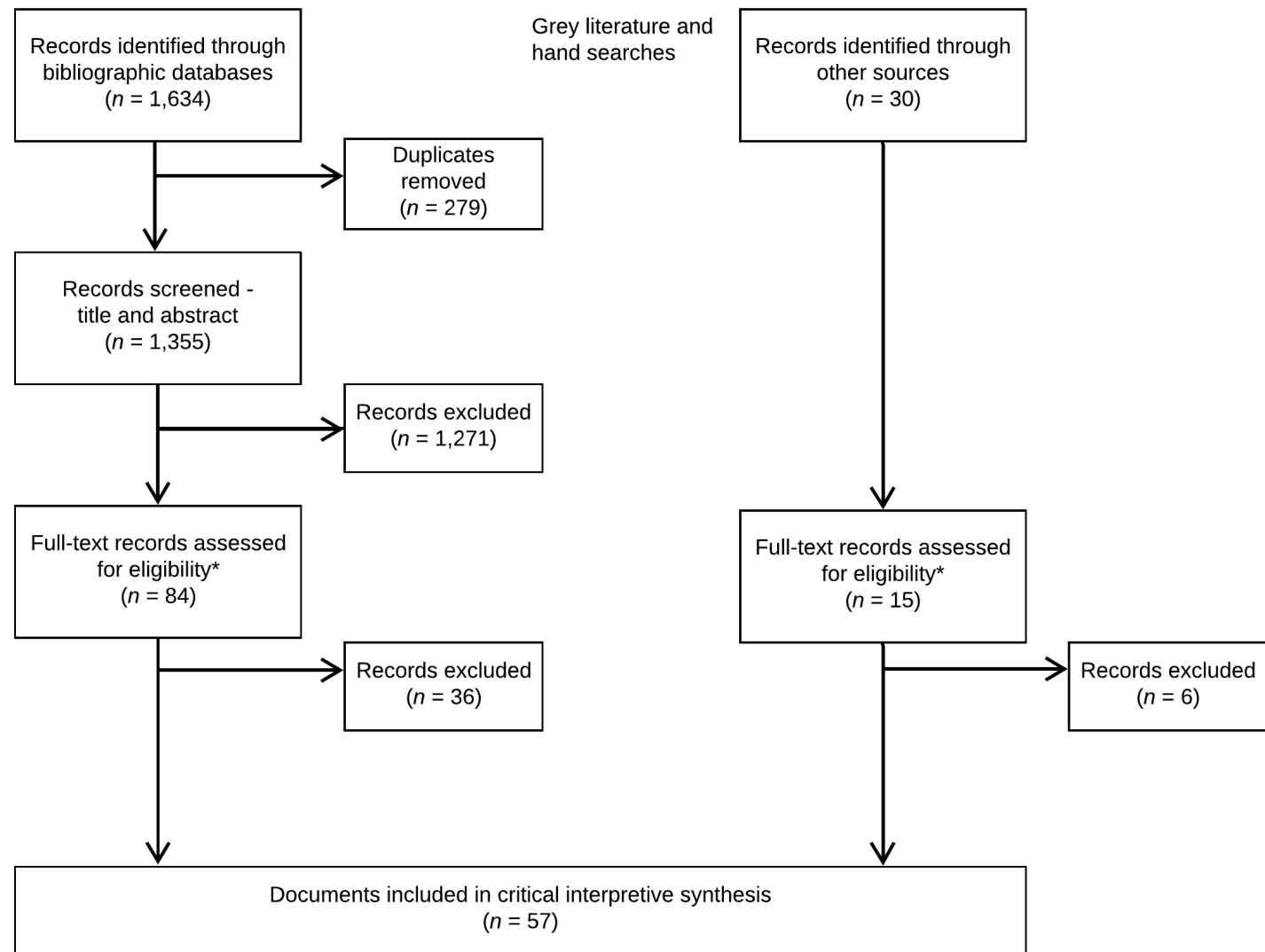

Figure 2 Literature search and study selection flow diagram.

\section{Additional evidence sources}

We conducted $31 \mathrm{KI}$ interviews (mean length of $43 \mathrm{~min}$ ) and 5 focus groups with midwifery association members. Twenty-four CAM programme documents were included in the document review. We also analysed observations notes (255 pages) and audio recordings between researchers (CM and $\mathrm{KB})$.

\section{Synthesis}

Figure 3 presents the framework that emerged from our review and synthesis. The framework illustrates the drivers and key-enabling elements that impact the sustainability of midwifery associations. These components are organised into three interconnected contexts: outer, organisational and core values of the association. They serve as a road map to support midwifery associations' navigation of the interconnected contexts. Below we describe the key components for midwifery association strengthening in which facilitators and mitigating barriers are addressed and summarised in table 1 . Table 2 aligns with the first and contains illustrative quotations organised by the key components presented in the framework.

\section{Key drivers for midwifery association strengthening Outer context}

Results showed that sustainable midwifery associations are influenced by the role, regulation and integration of midwifery within a given context, which is shaped by the political system (where decisions about midwifery integration will be made), health system arrangements (where midwives provide SRHR services) ${ }^{19} 27$ and the education system (where midwives are educated).

Political structures including international agreements, public policies, and the governmental agendas of dominant political parties shape the development of the midwifery workforce and profession, and influence efforts to strengthen midwifery services. ${ }^{2}$ Midwifery associations are agents for the profession, whose capacity to influence policy is determined by surrounding institutions and structures. ${ }^{27}$ Interview data showed changes in government created delays in achieving midwifery associations' goals such as regulation of the profession or involvement in national SRHR decision-making processes.

The overarching categories of health system arrangements are inter-related and include: (1) governance, which is focused on health system structures including policy and professional authority; (2) financial includes health financing and health professional payment mechanisms; and (3) health services delivery including how and where services are provided. ${ }^{28}$ Governance arrangements regulate health professions such as midwifery, however, in many countries midwives are inappropriately regulated or there is no legislation recognising midwifery as an autonomous profession. ${ }^{16}$ Our findings showed that the lack of understanding of midwifery as an autonomous profession led to the disappearance of midwifery on political agendas by health system decision-makers within governance structures. This disregard resulted in downstream impacts on other health system arrangements. For 


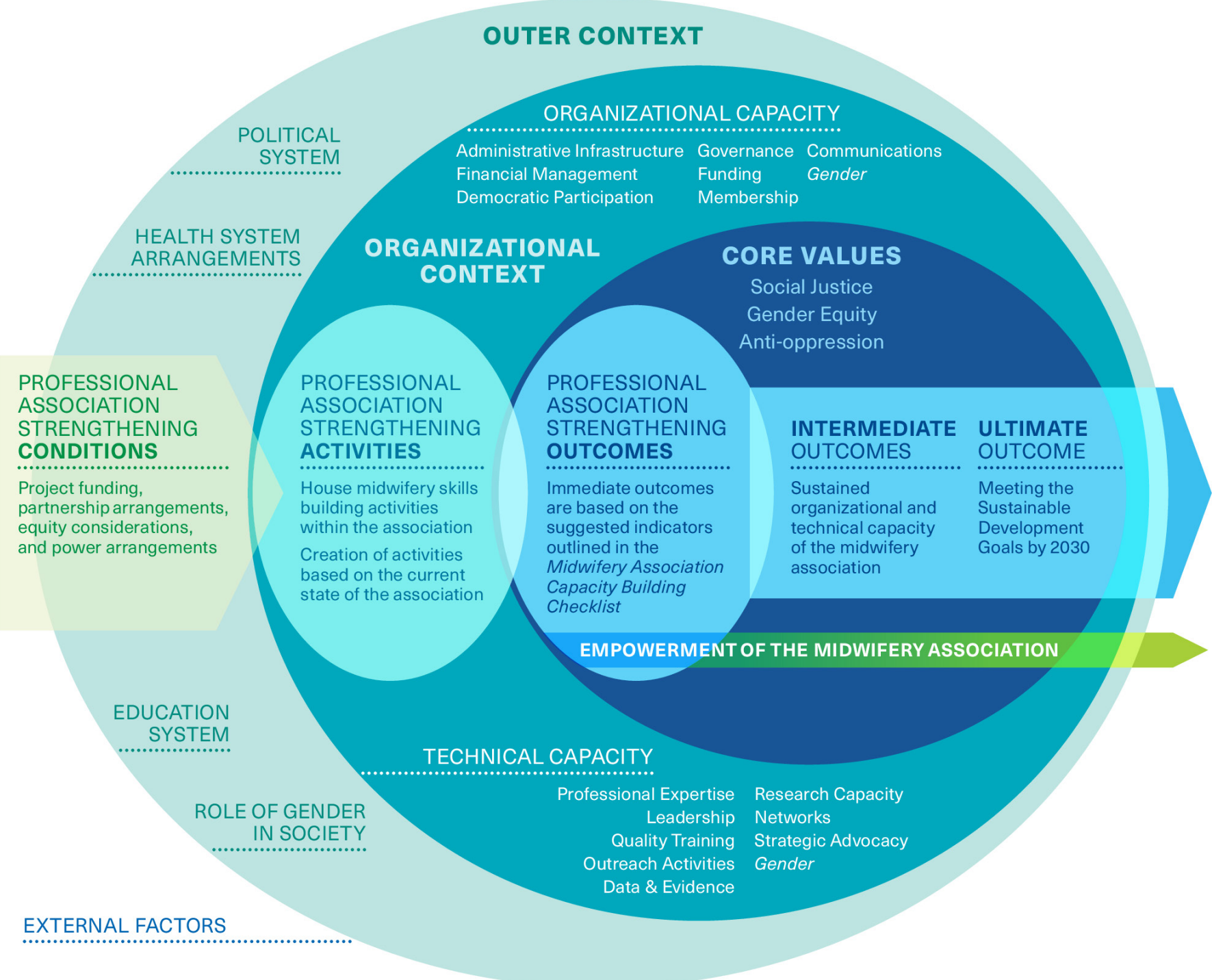

Figure 3 Framework for midwifery association strengthening.

example, participants noted a lack of clarity about the definition and role of a midwife within the health system, resulting in inappropriate deployment and remuneration. Lastly, with respect to the context where services are delivered, multiple barriers were raised (lack of personal safety, water, electricity, equipment and materials) which rendered the work of midwives impossible to carry out.

Inadequate remuneration of midwives impacted their ability to pay membership dues and become association members, which negatively impacted midwifery associations' financial viability and increased their precariousness. In contrast, strong midwifery associations played a key role negotiating appropriate work conditions and salaries for midwives with governments. ${ }^{16}$ Our results showed that midwifery associations advocated for effective mechanisms for regulation and for improved service delivery arrangements, including: (1) how midwives are deployed; (2) if midwives are appropriately positioned (eg, rather than filling in nursing positions); (3) the skill mix (eg, role performance, expansion and working in interprofessional teams); (4) the availability of and timely access to midwifery care (eg, workforce supply and distribution); (5) how midwifery care is provided and (6) where care is provided (eg, site of health service delivery, physical structure and equipment).

Six key areas in which midwifery associations enhanced the quality of midwifery education to enhance credibility and facilitate integration into health systems included: (1) advocating for accredited education programmes; (2) advising on quality standards for clinical learning; (3) providing continuing professional development; (4) creating student chapters within associations hereby attracting quality students and young leaders to the profession; (5) participating in national policy SRHR dialogues and (6) establishing professional competency assessments. $^{12689141629-42}$ Access to continuing education through midwifery associations was strongly linked with empowerment, increased sense of professional belonging, and respect and status of the profession, thereby influencing the status of the association. ${ }^{38}$ 
Table 1 Key components for midwifery association strengthening

Context and element

Description of components to strengthen midwifery associations including facilitators and mitigating barriers

Outer context

Political system

- The 3i framework helps to understand the political system factors that constrain or enable midwifery within health systems and consists of three main components: (1) institutions; (2) interests and (3) ideas ${ }^{72}$

- Institutions-midwifery associations can face structural barriers to integration as a result of government structures (eg, the political arrangement in a given context and mandates that influence SRHR policies) and policy legacies (eg, policies shape the way midwifery care is organised in the health system)

- Interests - collaboration across professional associations can come together and play a strong role in political lobbying (facilitator) or mitigating competing interests from other professional associations (eg, nursing), or discrimination (eg, some physician interest groups that seek to limit establishing midwifery as an autonomous profession) (barrier)

- Ideas - societal values regarding the medical model (eg, medicalisation of the birth process and associated valuing of physician and hospital-based care) and gender equity

\begin{tabular}{|c|c|}
\hline Health system arrangements & $\begin{array}{l}\text { Health systems factors include: (1) governance; (2) financial and (3) delivery }{ }^{28} \\
\text { - Governance arrangements that recognise midwifery as an autonomous profession and acknowledge } \\
\text { the role of midwifery associations advocating for legislation that codifies self-regulation and } \\
\text { autonomous practice } \\
\text { - Financial arrangements that include mechanisms to raise revenue to finance the health system and } \\
\text { remuneration for sexual and reproductive health services by midwives, which by extension impacts the } \\
\text { financial viability of midwifery associations } \\
\text { - Delivery arrangements that focus on how midwives are delivering health services within the health } \\
\text { system, and acknowledged expertise of midwifery associations to inform appropriate scope and role of } \\
\text { the profession }\end{array}$ \\
\hline Education system & $\begin{array}{l}\text { Established accreditation systems to support quality of midwifery education programmes } \\
\text { Adoption of ICM's Global Standards for Midwifery Education and Essential Competencies for Midwifery } \\
\text { Practice } \\
\text { Education and enhanced knowledge are linked with empowerment of the profession and midwifery } \\
\text { associations }\end{array}$ \\
\hline Role of gender in society & $\begin{array}{l}\text { Recognise that the social construction of gender influences the relationship that midwifery associations } \\
\text { have with authority and leadership }\end{array}$ \\
\hline \multicolumn{2}{|l|}{ Organisational context } \\
\hline Administrative infrastructure & $\begin{array}{l}\text { Establish a base-level administrative infrastructure to support technical capacity } \\
\text { Includes the necessary space and tools in order to be able to carry out the organisational mission }\end{array}$ \\
\hline Governance & $\begin{array}{l}\text { Establish best practice governance systems to manage the work of the association } \\
\text { The capacity of the midwifery association will determine the complexity of the governance structure }\end{array}$ \\
\hline Financial management & $\begin{array}{l}\text { Develop a concrete plan and system for financial oversight of the association } \\
\text { Develop yearly budgets to align with the association's priorities and strategic plan }\end{array}$ \\
\hline Democratic participation & $\begin{array}{l}\text { Understand and address the two main factors that influence democratic participation: } \\
\text { - the broader sociopolitical conceptualisations of democracy and historical impacts within a given } \\
\text { context; and } \\
\text { - the shared values and beliefs of the midwifery association and creating contextually relevant equitable } \\
\text { democratic procedures }\end{array}$ \\
\hline Communications & $\begin{array}{l}\text { Develop a communications strategy to support advocacy (technical capacity) } \\
\text { Four levels of communication: } \\
\text { - internal communications, which includes from board members communicating to each other (eg, } \\
\text { - meeting minutes), as well as communications from board to staff; } \\
\text { - groups and newsletter); } \\
\text { - to networks (eg, government and international community); and } \\
\text { - to the public through a range of media (public education) }\end{array}$ \\
\hline
\end{tabular}


Table 1 Continued

\begin{tabular}{ll}
\hline Context and element & $\begin{array}{l}\text { Description of components to strengthen midwifery associations including facilitators and mitigating } \\
\text { barriers }\end{array}$ \\
\hline Gender & Establish an equitable governance structure that ensures inclusivity and diversity of representation, \\
& particularly in terms of the gender and ethnicity of the board \\
& Equitable governance structure reinforces equitable representation within membership
\end{tabular}

Technical capacity

Midwifery professional
expertise

Leadership
- Establish a strong body of professional knowledge within midwifery (fostered by quality continuing education), and credibility and external recognition of the expertise held within the midwifery association

- Advance leadership within midwifery associations, which consists of:

1. membership's ability to influence and contribute to leadership within the broader system (political, health and/or social) through outreach activities;

2. an organisational leader to advocate to push forward the aims of the association externally in public and political spheres; and

3. the internal capacity of the association's leadership to manage the organisation appropriately (eg, democratic processes, accountability, transparency and succession planning)

\begin{tabular}{|c|c|}
\hline Quality midwifery training & $\begin{array}{l}\text { Ensure the midwifery association is working with midwifery education programmes to support quality } \\
\text { preservice and in-service education opportunities for members }\end{array}$ \\
\hline SRHR outreach activities & $\begin{array}{l}\text { Develop association-led SRHR community outreach activities } \\
\text { Assist in improving overall health and legitimising the organisation's role in the delivery of sexual and } \\
\text { reproductive health services }\end{array}$ \\
\hline Data and evidence & $\begin{array}{l}\text { The midwifery associations' ability to own, collect and/or share data to inform local midwifery practice and } \\
\text { standards (includes monitoring and evaluation and gender analyses) }\end{array}$ \\
\hline Networks & $\begin{array}{l}\text { Create strong alliances and networks at all levels (local, provincial, national and international) through } \\
\text { strategic activities } \\
\text { Twinning, particularly partnerships of similar contexts are a powerful alliance tool }\end{array}$ \\
\hline Gender & $\begin{array}{l}\text { Develop the skills within the association to create a gender equity and social inclusion policy and } \\
\text { undertake their own gender analysis } \\
\text { Includes having the appropriate resources to implement recommendations from the analysis }\end{array}$ \\
\hline Values & $\begin{array}{l}\text { Values are embedded and at the core of midwifery as a profession and the association by extension } \\
\text { Midwifery associations can build core values centred on principles of: } \\
\text { - social justice; } \\
\text { - gender equity; and } \\
\text { - anti-oppression }\end{array}$ \\
\hline
\end{tabular}

ICM, International Confederation of Midwives; SRHR, sexual and reproductive health and rights.

Forces and events outside of the political and health system can influence midwifery associations' capacitybuilding efforts or reorient their strategic planning. Specifically, external shocks to the system, such as pandemics, climate change, global economic crises, and natural disasters can erode women and girls' stability and safety (eg, by increasing gender-based violence). Shifts in resource allocation away from SRHR services delivery further impact the viability and power of midwifery associations. Conversely, our observations identified that some external shocks (eg, COVID-19 pandemic) presented a window of opportunity for midwifery associations to support quality clinical care through training, providing personal protective equipment to frontline midwives and creating practice guidelines.

Organisational context

Within the organisational context, we defined the capacity of midwifery associations as two reciprocal concepts, organisational and technical, which are further divided into key subcomponents outlined. ${ }^{6}$ Organisational capacity is the ability of the association to operate sustainably as an organisation. ${ }^{6}$ A base-level organisational capacity is needed to grow technical capacity and thus increase the organisation's sustainability and impact in strengthening the profession. We identified eight 
Table 2 Illustrative quotations organised by the key components for midwifery association strengthening

\section{Context and element}

\section{Illustrative quotations}

\section{Outer context}

Political system

Health system

arrangements

Role of gender in society
- 'The situation in the country, it really prevents the profession and the activities of the SRHR from progressing. For example, as soon as there is instability, we see changes in government. For example, the government that was there may be well, well, well involved in the midwifery project, well involved in the midwifery strategy. But when you take that from the government, from we're going to come with another government, we're back to zero. You could say that there's not really any continuity in the things of the state.' (KI \#1, translated from French)

- 'They have to do this in an environment where those midwives and those nurses are not getting paid, and when and if they get paid, they get paid probably like $\$ 15.00$ per month. So, even the salary they do receive it, it's not enough for them to survive.' (KI \#24)

- 'This is a really important point, and above all, with the number of midwives in the country, there are many midwives so far who don't have a job yet. That is to say, there are midwives who are qualified and who are in the country, but who are not working. So, this is a really negative problem for the reduction of maternal mortality.' (KI \#7, translated from French)

Education system 'I could also say in terms of policies, if we had something to do for the association, we should have an accreditation for the profession. Without accreditation, you can't have a strong profession. You have to have terms of renewal of licence, up-to-date training diplomas, continuing education.' (KI \#1, translated from French)

- 'I think the involvement of doctors themselves in designing and implementing development across the world in global health and outside of it, because a contextual piece is just that a lot of the development practitioners that I met in Uganda or South Sudan too, they're medical doctors who actually in some better paid positions. They're in humanitarian relief. They're in this. They're in government. They're medical doctors.' (KI \#13) (quote relates to authority and leadership being primarily medical model and male-dominated)

\section{External factors}

\section{Organisational context}

Administrative infrastructure

- 'They had an office space, a small office space that was paid through CAM with other funds, but they didn't actually have staff. This is what we've been working on basically for the past year, so now we have - there's a team, a project officer, a finance person, a secretary, an administrative assistant, security guards, and they moved into a bigger space. That was all at the beginning of last year basically where we had hired the team, and then when you hire a team, you have to put in place all the procedures, like admin, human resources.' (KI \#21)

Governance $\quad$ 'And above all, learn to decentralise. Get everyone involved. Get everyone involved in the management
of the association. So that everyone can feel concerned in their own corner. You are a sectionalist, but
you should feel that you are... it concerns you. And also to organise elections from time to time. Organise
elections. Organising elections like this allows people to improve. It allows people to improve things and it
allows everyone to make a contribution to the organisation.' (KI \#2, translated from French)

Financial management

- 'The mentoring I liked, first of all, is how to manage a professional association. Another thing, we didn't have a plan. We were working, but we didn't have an annual plan that showed the midwife's activities. We were shown how to make a plan of activities and how to manage projects as well. It was a reinforcement.' (KI \#2, translated from French)

$\begin{array}{ll}\begin{array}{l}\text { Democratic } \\ \text { participation }\end{array} & \text { 'People with association-strengthening expertise in Canada have an assumption of a democratic landscape } \\ \text { and is not applicable for our partners in non-democratic situations.' (KI \#31) } \\ \text { 'Before the training, the association was authoritarian, a hierarchy. Now, the dynamics have changed, and } \\ \text { the leaders are now also the care providers.' (Focus group participant, translated from French) } \\ \text { Funding } \\ \text { 'The association has not yet reached the level of financial autonomy. They depend on partners; they have } \\ \text { no sources of income. The contributions are lower and that's it. They are not yet free enough. We need to } \\ \text { support them, but by targeting the area of support that is really essential for their maturity.' (KI \#4, translated } \\ \text { from French) } \\ \text { Membership } \\ \text { 'So now we are trained to make sure that we bring up young, young, young midwives to love the } \\ \text { association, to work for the association. When we are stepping down, there are young midwives who can } \\ \text { take over, who knows they are succession, and so on.' (KI \#6) } \\ \text { Communications } \\ \text { 'I manage the social media accounts [for the association], so I see how - midwives reach out constantly to } \\ \text { me every day asking for, "Hey, how do I join? How do I, this, and this? What do you guys offer? Are there } \\ \text { learning opportunities?" People are eager for knowledge. They really are.' (KI \#15) }\end{array}$


Table 2 Continued

\section{Context and element}

\section{Illustrative quotations}

- 'Work is work, and people (midwife association members) should be paid for work, and then choosing to engage yourself in building your profession and building your association because you believe in it, that could be voluntary, but - making sure the people are compensated, especially in global south context, because they're so under compensated.' (KI \#7) (quote captures pay inequity related to gender)

Technical capacity

$\begin{array}{ll}\text { Midwifery } & \text { 'This is across the board - consultants found this when they went, that it was totally observed, it's been } \\ \text { professional } & \text { reported, that because [the association] was going out in the regions in the rural areas and delivering training } \\ \text { expertise } & \text { to midwives, a whole bunch of district health officers and regional health bureaucrats and doctors gained } \\ & \text { understanding of what [the association] was and what midwives were and [the association's] own kind of } \\ & \text { capacity to influence things and capacity to support their members grew as an unintended benefit of those } \\ & \text { clinical skills trainings.' (KI \#19) } \\ \text { 'Once you build a strong association, then that association is going to keep advocating for its members. It's } \\ \text { going to keep advocating for the profession. It's going to keep advocating for women and children and their } \\ \text { rights.' (KI \#17) } \\ \text { Leadership } \\ \text { 'First of all, to strengthen the leadership of management - the executive leadership committees, as well } \\ \text { as the national and provincial leadership committees. And above all, learn to decentralize. Get everyone } \\ \text { involved. Involve everyone in the management of the association. So that everyone can feel concerned in his } \\ \text { or her own corner.' (KI \#2, translated from French) }\end{array}$

Quality midwifery
training

- 'It used to be the doctor who trained others in EmONC and now it is the midwives who are called by the government. Midwifery trainers have been able to advocate for the presence of midwives in EmONC trainings and even to include traditional birth attendants in rural areas.' (Focus group participant, translated from French)

SRHR outreach activities

- 'For example, in the north, we had a screening day for cervical cancer. And at the same time, we did the treatment for women who have precancerous lesions and at that time, we promoted the profession.' (KI \#7)

Data and evidence 'But also developing their own monitoring and evaluation tools so that it may fit within (the) context. And with the sustainability. So, (the association) is able to apply certain tools in the next five to ten years, so that's what I think capacity building for the association will be necessary to move forward.' (KI \#7)

Research capacity and knowledge translation

- 'They are constantly, constantly building that capacity and another good example of - and this is actually a success story for that - is that they are building the capacity to write proposals. So, now they get funding directly (...), we have a local fund, and now they have funding.' (KI \#24)

- 'I think it's very important. You have so much capacity already, but if you're thinking of sustainability, it's how do you move on? How do you get that proposal writing capacity, research, dissemination?' (KI \#23)

Networks 'Because when we see what others in other countries are doing, it helps us, so that we can work much more
at the level of our institutions, at the level of the country to help women in our work.' (KI \#7, translated from
French)

Strategic advocacy ' 'It started off as just the three of them - three or four, and now they've grown, and they're definitely - yeah, everything that they do, and the connections that they have. I think they're super well placed. Just today, talking about, let's reach out to the Department of Gender and the Ministry of Health. Those are key connections to have.' (KI \#19)

- 'Now we can go and talk, even within the Ministry (...) I presented with confidence (...) I can come up with the funding and convincing people this is the reality. This is also the result of this relationship.' (KI \#16)

Gender
'I was trying to think whether there is a gender framework or model to capture specifically the impact of
the [midwifery] association on gender equality (...) the only one that comes to mind is the gender at work
framework (...) and I think in theory it is possible to take a framework, operationalize it with specific metrics
(...) and use it to measure if the association has impacted gender equality.' (KI \#25) (quote captures how
midwifery associations can measure gender equity with relation to programme activities)
Values
'When you have disempowered midwives, you don't have good quality care. You really just don't, and you
don't have any opportunity to input into national programs or local programs because there is not a respect
for the midwives who would like to have their voices heard at those tables.' (KI \#22)

CAM, Canadian Association of Midwives; EmONC, emergency obstetric and newborn care; KI, key informant; SRHR, sexual and reproductive health and rights.

elements within organisational capacity: (1) administrative infrastructure ${ }^{3671739} ;(2)$ governance ${ }^{43-46} ;(3)$ financial management ${ }^{1843} ;(4)$ democratic participation ${ }^{43446}$; (5) funding ${ }^{43} 47$; (6) membership ${ }^{43}$; (7) communications $^{3434448}$ and (8) gender.
External factors can also impact associations at an organisational capacity level (eg, sudden illness, death or disability of a key association member, loss of significant funder, allegations of malpractice of a highprofile member or misappropriation of funds). ${ }^{44}$ While 
organisational crises cannot be anticipated, midwifery associations can reduce their impacts through strong administrative infrastructure, governance, financial management and communications strategies.

Technical capacity is conceptualised as the association's 'core business,' and refers to the ability to support and maintain effective programming and activities to strengthen the profession within political, health and education systems. ${ }^{6}$ We identified nine elements within technical capacity: (1) midwifery professional expertise $^{2} 4549$; (2) leadership ${ }^{6051}$; (3) quality midwifery training ${ }^{6}{ }^{16} 4451-53$; (4) SRHR outreach activities; (5) data and evidence ${ }^{2950}$; (6) research capacity and knowledge translation $^{954}$; (7) networks ${ }^{134415556}$; (8) strategic advocacy (an outcome of networks) 378164345485758 and (9) gender. $^{59}$

The reciprocal relationship of organisational and technical capacity was revealed in our qualitative evidence. When midwifery associations housed programmes to increase in-service midwifery capacity, such as emergency skills training (emergency obstetric and newborn care (EmONC)), both the organisational and technical capacity of the association was increased. To effectively deliver EmONC training, associations were trained in programmatic and administrative skills and team building. These skills were generalisable and transferable to efficiently running the association. Furthermore, when midwifery associations trained their executive members to be EmONC facilitators, evaluators, mentors and supervisors, these midwives continued to provide training after project completion. Embedding skills in the executive membership built external recognition for the association's capacity to train midwives to global standards.

In-service training was also identified as a way to raise associations' profiles within facilities, hospitals and health networks. Increased visibility and credibility assisted the association to effectively carry out other activities (eg, overseeing accreditation of midwifery education programmes and lobbying governments for midwifery inclusive policies). Additionally, midwives themselves were more likely to understand the role of their association and become members. Associations were then able to better advocate for their members at the institutional and governmental levels for appropriate remuneration mechanisms. Finally, increases in membership and EmONC training became vital sources of income for the association, that then supported and sustained organisational capacity.

\section{Gender}

Gender and its intersections (ie, race, ethnicity, religion) are a unique and cross-cutting consideration impacting each context. The role of gender within society is an inseparable component of the outer context. ${ }^{2} 193334436061$ The social construction of gender impacts the value placed on women in a given country, and in turn the value placed on predominately women-led midwifery associations within that society. ${ }^{19}$ Gender norms influenced the relationships that associations had with decision-makers resulting in a lack of visibility and credibility of the organisation. ${ }^{234}$ For example, our results showed that decision-makers within health sectors tended to be male physicians. This gender dichotomy influenced midwifery associations' relationships with authority and leadership due to an overall lack of societal respect for women. ${ }^{43}$ Finally, strains on health systems caused by long-term events, such as conflict, political coups or market inflation, impact gender disproportionately and thus threatened associations' sustainability.

Within the organisational context, gender considerations for organisational capacity include creating equitable governance structures within the association that support women in leadership and enhance diversity in the board and general membership. Technical capacity consisted of the association's ability to conduct their own gender analysis and have the resources to appropriately respond to recommendations, including applying a gender lens to the association's external environment, organisational structure, and how they provide clinical support and training for members. Our data showed that often gender analyses were an afterthought and were completed by often costly external international consultants, thereby limiting the timeliness, relevance and local applicability of findings.

\section{Core values of midwifery associations}

Midwifery associations' core values underpin their organisational activities and outputs; align closely with the organisation's mission, vision and strategic plan; and shape the organisation's role in the community and the key programming/services offered. Within midwifery associations, we identified social justice, equity and antioppression as the most common core-espoused organisational values. $831323537455962-65$ A universal implicit value of midwifery associations is that they are working towards a common goal of improving SRHR. Importantly, each association has its own perception of the benefits that it brings to the community, and its values are highly context specific.

Despite outward organisational values, our results revealed that midwifery associations' internal culture can be positively or negatively influenced by personal privileges and power, such as sexism, ethnicism or classism. One challenge that participants identified was the lack of transparency of an association's board to its members and a tendency to disregard procedures for democratic succession planning. Some participants described being excluded from opportunities for leadership based on their age or social position. Members needed to have open discussions that encourage equitable distribution of leadership roles and perceived this as important to sustaining participation in the association over time.

Empowerment emerged as an important outcome of midwifery association strengthening and is identified in the literature as the "powerful catalyst for positive change' ${ }^{59}$ It is founded on the sense of value and credibility association members felt as a direct product of 
success, both internal and external, to the organisation. For example, feeling empowered was described as having impact, being autonomous, participating in institutional decision-making and policymaking, economic opportunity, access to education and professional self-worth. ${ }^{38}$ In circumstances where midwifery associations improved their capacity via the collaboration with other midwifery associations, trust and reciprocity lead to overall mutual empowerment. Participants described their empowerment motivated them to advocate for SRHR, and for the inclusion of midwives in decision-making, leading to improved capacity of the associations. Empowerment is a positive feedback loop, and as the capacity of the association is built, individuals are empowered, and the organisational capacity improves, and so on. ${ }^{62}$

\section{DISCUSSION}

Our study is the first to generate theory and a framework for sustainable midwifery association strengthening in order to increase the impact of midwifery associations to advance the profession and ultimately improve SRHR. We have also created an open-access companion to the framework, Midwifery Association Capacity Building Checklist, that operationalises the theory presented and is a practical tool for midwifery associations. Our framework is applicable to midwifery associations and external partners or projects as it details and categorises capacity into technical and organisational factors so that these components can be applied to inform logic models for programme development. Use of the framework can ensure that activities align with associations' needs, reinforce the likelihood of long-term sustainability past project closure, and ensure that the planned capacitybuilding activities are context specific and achievable within the association's current capacity.

Most research about midwifery association strengthening has focused on twinning relationships between associations. 83037596266 Prior scholarship suggests that strengthening professional associations may improve health systems and health outcomes (eg, through ensuring the quality of education and regulation). ${ }^{8} 18$ However, while midwifery associations globally strive for stronger involvement in the SRHR policymaking process, their contributions are hindered by lack of professional recognition or understanding of the role of midwifery in health and political systems, ${ }^{216} 19$ and marginalisation of the profession driven by gender inequality and the substandard status of women-dominated health professions. ${ }^{1952606768}$ These inequities give rise to other structural challenges such as lack of governance or absence of regulatory frameworks, and result in poor integration of the profession into health systems (eg, lack of midwifery education accreditation mechanisms, absent or poor remuneration, restrictions on midwives' autonomy and limited ability to generate research). ${ }^{1969}$

Our framework's attention to the role of gender provides direction to addressing the challenges outlined above. Capacity assessments require a feminist process, using a gender lens which also accounts for intersecting identities (eg, ethnicity, indigeneity and disability). Strong equity and anti-colonial frameworks foster collaboration and consensus thereby empowering women's leadership within associations. Principles of gender equity are shared values when working to improve SRHR. Integrating these elements concretely into project inception and operationalisation of activities empowers project hosts (ie, midwifery associations). Our findings demonstrate that empowerment in transnational projects supports sustainable outcomes within midwifery associations with regard to both technical and organisational capacity. ${ }^{3759} 7071$

The main strength of our research is the richness of the data we compiled through multiple sources and the collaborative spirit of our transnational research consortium. The use of multiple sources of evidence obviated the need to rely on the very limited relevant published literature as the only input to theory generation and allowed us to address the lack of research evidence regarding the role of midwifery associations in improving SRHR and strengthening health systems. Our approach during the research process promoted an equitable transnational collaboration and the integration of multiple perspectives thus increasing the research's trustworthiness.

A limitation was that we were unable to visit all of CAM's current partner midwifery associations due to logistical challenges specific to political instability and travel to fragile states. While we collected qualitative data from these contexts through virtual means, we recognise that time spent in-country is an important source of evidence and important to understanding midwifery associations working in challenging contexts.

\section{CONCLUSION}

Midwifery associations are key enablers to strengthening their profession across political, health and education systems. Building strong associations is the lynchpin in furthering the status of midwifery, improving gender equity, and reducing maternal and newborn mortality and morbidity. Our framework will support evidenceinformed investments in midwifery associations so that they can play a leadership role in country's responses to the gendered impacts of crises on SRHR and in more broadly addressing gender-related inequities related to SRHR.

\section{Twitter Cristina Mattison @MattisonPhD and Elizabeth Darling @LizDarlingRM}

Acknowledgements Since the drafting of this manuscript, we have lost Dr. Sebalda Leshabari, a global leader in midwifery research. We are grateful for the opportunity to have learned from Dr. Sebalda and her many contributions to this research.

Contributors CM, KB, JR and ED initiated the project. CM and KB designed the research, collected and analysed the data, interpreted the results, and wrote the text in collaboration with AK, AP, EH, JR, ED and SL.

Funding This study was funded by Mitacs (grant number: IT1531).

Competing interests None declared. 
Patient and public involvement Patients and/or the public were not involved in the design, or conduct, or reporting, or dissemination plans of this research.

Patient consent for publication Not required.

Ethics approval We obtained ethics approval from the Hamilton Integrated Research Ethics Board (HiREB, protocol \#7489) at McMaster University, Hamilton, Canada and Laurentian University's Research Ethics Board (LUREB protocol \#6018380) at Laurentian University, Sudbury, Canada prior to data collection.

Provenance and peer review Not commissioned; externally peer reviewed.

Data availability statement Data are available upon request. All data contributing to the analyses in this study are stored on a secure network and not publicly available in order to protect participant confidentiality.

Open access This is an open access article distributed in accordance with the Creative Commons Attribution Non Commercial (CC BY-NC 4.0) license, which permits others to distribute, remix, adapt, build upon this work non-commercially, and license their derivative works on different terms, provided the original work is properly cited, appropriate credit is given, any changes made indicated, and the use is non-commercial. See: http://creativecommons.org/licenses/by-nc/4.0/.

ORCID iD

Cristina Mattison http://orcid.org/0000-0001-7210-0690

\section{REFERENCES}

1 Chamberlain J, McDonagh R, Lalonde A, et al. The role of professional associations in reducing maternal mortality worldwide. Int J Gynaecol Obstet 2003;83:94-102.

2 Lopes SC, Titulaer P, Bokosi M, et al. The involvement of midwives' associations in policy and planning about the midwifery workforce: a global survey. Midwifery 2015;31:1096-103.

3 Shaw D. Advocacy: the role of health professional associations. Int J Gynaecol Obstet 2014;127 Suppl 1:S43-8.

4 Shamian J. Interprofessional collaboration, the only way to save every woman and every child. Lancet 2014;384:e41-2.

5 Taylor DJ. Professional leadership in obstetrics and gynecology and its contribution to millennium development goal 5. Int J Gynaecol Obstet 2012;119 Suppl 1:S42-4.

6 Lalonde AB, Menendez H, Perron L. The role of health professional associations in the promotion of global women's health. $J$ Womens Health 2010;19:2133-7.

7 Andrews $\mathrm{H}$, Perron L, Vander Plaetse B, et al. Strengthening the organizational capacity of health professional associations: the FIGO logic toolkit. Int J Gynaecol Obstet 2013;122:190-1.

8 Sandwell R, Bonser D, Hebert E, et al. Stronger together: midwifery twinning between Tanzania and Canada. Global Health 2018;14:123.

9 Homer CSE, Friberg IK, Dias MAB, et al. The projected effect of scaling up midwifery. Lancet 2014;384:1146-57.

10 Renfrew MJ, McFadden A, Bastos $\mathrm{MH}$, et al. Midwifery and quality care: findings from a new evidence-informed framework for maternal and newborn care. Lancet 2014;384:1129-45.

11 Starrs AM, Ezeh AC, Barker G, et al. Accelerate progress-sexual and reproductive health and rights for all: report of the GuttmacherLancet Commission. Lancet 2018;391:2642-92.

12 ten Hoope-Bender P, de Bernis L, Campbell J, et al. Improvement of maternal and newborn health through midwifery. Lancet 2014;384:1226-35.

13 UNFPA. The maternal and newborn health thematic fund annual report 2019. New York: United Nations Population Fund, 2019.

14 WHO. Strengthening quality midwifery education for universal health coverage 2030: framework for action. Geneva: World Health Organization, 2019.

15 Nove A, Friberg IK, de Bernis L, et al. Potential impact of midwives in preventing and reducing maternal and neonatal mortality and stillbirths: a lives saved tool modelling study. Lancet Glob Health 2021;9:e24-32.

16 Castro Lopes S, Nove A, Ten Hoope-Bender P, et al. A descriptive analysis of midwifery education, regulation and association in 73 countries: the baseline for a post-2015 pathway. Hum Resour Health 2016;14:37.

17 SOGC. Strengthening organization capacity of professional health associations. Ottawa: The Society of Obstetricians and Gynaecologists of Canada, 2009.

18 Dawson A, Brodie P, Copeland F, et al. Collaborative approaches towards building midwifery capacity in low income countries: a review of experiences. Midwifery 2014;30:391-402.
19 Mattison CA, Lavis JN, Wilson MG, et al. A critical interpretive synthesis of the roles of midwives in health systems. Health Res Policy Syst 2020;18:77.

20 Dixon-Woods M, Bonas S, Booth A, et al. How can systematic reviews incorporate qualitative research? A critical perspective. Qualitative Research 2006;6:27-44.

21 Dixon-Woods M, Cavers D, Agarwal S, et al. Conducting a critica interpretive synthesis of the literature on access to healthcare by vulnerable groups. BMC Med Res Methodol 2006;6:35.

22 Charmaz K. Constructing grounded theory. London: Sage, 2014.

23 Mertens DM. Transformative research and evaluation. New York: Guilford Press, 2008.

24 Abimbola S. The foreign gaze: authorship in academic global health. BMJ Glob Health 2019;4:e002068.

25 Hankivsky O. Intersectionality 101. The Institute for Intersectionality Research \& Policy, 2014

26 Abrams JA, Tabaac A, Jung S, et al. Considerations for employing intersectionality in qualitative health research. Soc Sci Med 2020;258:113138.

27 McKenzie A, Sokpo E, Ager A. Bridging the policy-implementation gap in federal health systems: lessons from the Nigerian experience. J Public Health Afr 2014;5:82-7.

28 Lavis J. Health systems evidence: taxonomy of governance, financial and delivery arrangements and implementation strategies within health systems. Hamilton: McMaster Health Forum, 2017.

29 Ajuebor O, McCarthy C, Li Y, et al. Are the global strategic directions for strengthening nursing and midwifery 2016-2020 being implemented in countries? findings from a cross-sectional analysis. Hum Resour Health 2019;17:54

30 Bogren M, Erlandsson K. Opportunities, challenges and strategies when building a midwifery profession. findings from a qualitative study in Bangladesh and Nepal. Sex Reprod Healthc 2018;16:45-9.

31 Bvumbwe T, Mtshali N. Nursing education challenges and solutions in sub Saharan Africa: an integrative review. BMC Nurs 2018;17:3.

32 Dawson A, Kililo M, Geita L, et al. Midwifery capacity building in Papua New Guinea: key achievements and ways forward. Women Birth 2016;29:180-8.

33 Speakman EM, Shafi A, Sondorp E, et al. Development of the community midwifery education initiative and its influence on women's health and empowerment in Afghanistan: a case study. BMC Womens Health 2014;14:111.

34 Temmar F, Vissandjée B, Hatem M, et al. Midwives in Morocco: seeking recognition as skilled partners in women-centred maternity care. Reprod Health Matters 2006;14:83-90.

35 Maclean GD, Forss K. An evaluation of the Africa midwives research network. Midwifery 2010;26:e1-8.

36 Sheikh JI, Cheema S, Chaabna K, et al. Capacity building in health care professions within the Gulf cooperation Council countries: paving the way forward. BMC Med Educ 2019;19:83.

$37 \mathrm{Kemp}$ J, Bannon EM, Mwanja MM, et al. Developing a national standard for midwifery mentorship in Uganda. IJHG 2018;23:81-94.

38 Krubiner CB, Salmon M, Synowiec C, et al. Investing in nursing and midwifery enterprise: empowering women and strengthening health systems--A landscaping study of innovations in low- and middleincome countries. Nurs Outlook 2016;64:17-23.

39 Mudokwenyu-Rawdon C, Chaibva CN. Needs assessment and strengthening midwifery association in Zimbabwe. Afr J Midwifery Womens Health 2010;4:38-41.

40 Oliver K, Parolin Z. Assessing the policy and practice impact of an international policy initiative: the state of the world's midwifery 2014. BMC Health Serv Res 2018;18:499.

41 Uwizeye G, Mukamana D, Relf M, et al. Building nursing and midwifery capacity through Rwanda's human resources for health program. J Transcult Nurs 2018;29:192-201.

42 WHO. Who nursing and midwifery progress report 2008-2012. Geneva: World Health Organization, 2013.

43 American College of Nurse-Midwives. Professional association strengthening manual. Silver Spring: American College of NurseMidwives, 2016

44 FIGO. Strengthening organisational capacity of health professional associations. toolkit. London: International Federation of Gynecology and Obstetrics, 2012.

45 McQuide P, Millonzi K, Farrell C. Strengthening health professional associations. Chapel Hill: The Capacity Project, 2007.

46 Moyo N. ICM assists at a 'rebirth': the Midwives Association of Sierra Leone. Int Midwifery 2008;21:10-11.

47 Spies LA, Garner SL, Faucher MA, et al. A model for upscaling global partnerships and building nurse and midwifery capacity. Int Nurs Rev 2017;64:331-44.

48 Beyeza-Kashesya J, Kaharuza F, Murokora D. The advantage of professional organizations as Advocates for improved funding of 
maternal and child health services in Uganda. Int $J$ Gynaecol Obstet 2014;127 Suppl 1:S52-5.

49 Weenink J-W, Kool RB, Hesselink G, et al. Prevention of and dealing with poor performance: an interview study about how professional associations AIM to support healthcare professionals. Int J Qual Health Care 2017;29:838-44.

50 Waters KP, Zuber A, Willy RM, et al. Kenya's health workforce information system: a model of impact on strategic human resources policy, planning and management. Int J Med Inform 2013;82:895-902.

51 ten Hoope-Bender P, Lopes STC, Nove A, et al. Midwifery 2030: a woman's pathway to health. What does this mean? Midwifery 2016;32:1-6.

52 UNFPA-ICM. Investing in midwives and others with midwifery skills to save the lives of mothers and newborns and improve their health. New York: United Nations Population Fund, 2006.

$53 \mathrm{WHO}$. Midwives voices, midwives realities. Findings from a global consultation on providing quality midwifery care. Geneva: World Health Organization, 2016.

54 WHO. Strengthening midwifery toolkit. Geneva: World Health Organization, 2011.

55 Gualda DMR, Narchi NZ, de Campos EA. Strengthening midwifery in Brazil: education, regulation and professional association of midwives. Midwifery 2013;29:1077-81.

56 McCarthy CF, Voss J, Salmon ME, et al. Nursing and midwifery regulatory reform in East, central, and southern Africa: a survey of key stakeholders. Hum Resour Health 2013;11:29.

57 Homer CSE, Castro Lopes S, Nove A, et al. Barriers to and strategies for addressing the availability, accessibility, acceptability and quality of the sexual, reproductive, maternal, newborn and adolescent health workforce: addressing the post-2015 agenda. BMC Pregnancy Childbirth 2018:18:55.

58 Murphy PA. Listening to midwives. J Midwifery Womens Health 2017;62:7-8.

59 Cadée F, Nieuwenhuijze MJ, Lagro-Janssen ALM, et al. The state of the art of twinning, a concept analysis of twinning in healthcare. Global Health 2016;12:66.

60 Renfrew MJ, Ateva E, Dennis-Antwi JA, et al. Midwifery is a vital solution-What is holding back global progress? Birth 2019;46:396-9.
61 Zuyderduin A, Obuni JD, McQuide PA. Strengthening the Uganda nurses' and midwives' association for a motivated workforce. Int Nurs Rev 2010;57:419-25.

62 Cadée F, Perdok H, Sam B, et al. 'Twin2twin' an innovative method of empowering midwives to strengthen their professional midwifery organisations. Midwifery 2013;29:1145-50.

63 Canadian Coalition for Global Health Research. Partnership assessment toolkit. Ottawa: Canadian Coalition for Global Health Research, 2009.

64 Potter C, Brough R. Systemic capacity building: a hierarchy of needs. Health Policy Plan 2004;19:336-45.

65 Psaltis C. International collaboration as construction of knowledge and its constraints. Integr Psychol Behav Sci 2007;41:187-97.

66 Ndenga E, Uwizeye G, Thomson DR, et al. Assessing the twinning model in the Rwandan human resources for health program: goal setting, satisfaction and perceived skill transfer. Global Health 2016;12:4.

67 Day-Stirk F. Capacity development - a midwifery perspective. In: Kehoe S, Meilson J, Norman J, eds. Maternal and infant deaths: chasing millennium development goals 4 and 5. London: RCOG Press, 2010: 219-28.

68 Goodman S. Piercing the veil: the marginalization of midwives in the United States. Soc Sci Med 2007;65:610-21.

69 Filby A, McConville F, Portela A. What prevents quality midwifery care? A systematic mapping of barriers in low and middle income countries from the provider perspective. PLoS One 2016;11:e0153391.

70 Global Health Workforce Alliance. ICM global standards: essential to a universally agreed basic standard of midwifery education, 2020. Available: https://www.who.int/workforcealliance/media/news/2012/ icmstandards/en/ [Accessed 16 Dec 2020].

71 Upvall MJ. Building transformative global nursing partnerships. Res Theory Nurs Pract 2018;32:247-54.

72 Lazar H, Lavis JN, Forest P-G. Paradigm freeze: why it is so hard to reform health care in Canada. Montreal and Kingston: McGillQueen's University Press, 2013. 